\title{
The Empirical Research of the Influence of Leadership Positive Emotion on Counterproductive Work Behavior
}

\author{
Peng Qin, Yaozhong Liu \\ Management School, Jinan University, Guangzhou, China \\ Email: 381870831@qq.com
}

How to cite this paper: Qin, P., \& Liu, Y. Z. (2019). The Empirical Research of the Influence of Leadership Positive Emotion on Counterproductive Work Behavior. Psychology, 10, 877-902.

https://doi.org/10.4236/psych.2019.106057

Received: April 30, 2019

Accepted: May 17, 2019

Published: May 20, 2019

Copyright $\odot 2019$ by author(s) and Scientific Research Publishing Inc. This work is licensed under the Creative Commons Attribution International License (CC BY 4.0).

http://creativecommons.org/licenses/by/4.0/

\section{(c) (i) Open Access}

\begin{abstract}
Leader's emotion is one of the most influential factors of employee behavior in the workplace. The expression or of a leader's positive emotion can directly or indirectly affect the employee's work performance, especially the employee's Counterproductive Work Behavior (CWB). This paper systematically explains the internal mechanism how the leader's positive emotion affects employees' CWB through experimental methods, and uses the Emotions As Social Information Modle (EASI) to analyze and explain the research results. Finally, this study exposes the inner psychological process of Leader's positive emotion affecting employees' CWB through their own positive emotions, proving the moderating effect of leadership justice in this process, and this study enriches the results of the research field of CWB.
\end{abstract}

\section{Keywords}

Leader's Positive Emotion, CWB, Leadership Justice, Employee's Positive Emotions

\section{Introduction}

The employee's counterproductive work behavior (CWB) is a kind of negative behavior, which poses a threat or harm to the organization and organizational employee welfare. It is a self-issuance behavior, completely subject to the subjective will of the employee, so that employee can freely decide to engage with No. It still a role outside the behavior; the job responsibilities do not clearly stipulate that the employee must engage in or not engage in these behaviors. It is subordinate to the peripheral performance in employee performance, and the employee CWB is more negative than the organizational citizenship behavior. Negatively, the importance of employee CWB can be underestimated, which has a 
significant impact on the development of the entire organization, the working atmosphere of the entire team and the development of each employee's own career. According to Harper's research, 33\% to $75 \%$ of employees in the company have demonstrated CWBs such as theft, corruption, destruction of goods, and deliberate completion (Harper, 1990). Zhang, J. Y. surveyed the employees of the company with a sample of 20 domestic enterprises. In the daily work environment of various enterprises in China, there are 13 kinds of behavior that are not conducive to organizational production including language violence, physical violence, rude behavior, theft and destruction of property (Zhang \& Wang, 2008). Studies have found that only violations in the workplace will cause social losses of not less than $\$ 4.2$ billion per year (Bensimon, 1994), while employee theft will cause the organization to suffer losses of no less than $\$ 200$ billion per year (Greenberg, 1990). According to a survey conducted by the National Retail Security Survey, more than half of the 31.3 billion inventories lost in 2001 caused by employee theft, and the annual social loss caused by employee theft is increasing year after year. It is seen that CWB has become a serious problem that modern organizations need to solve urgently.

Based on people being a group of animals, our life is inseparable from the connection and communication with others. There is emotion in communication. Emotion is an instinct and a signal. It always conveys the process of interpersonal communication for us. The safety and danger signals are especially true in work situations. When employees communicate with their immediate supervisors, the emotions expressed by the leaders provide critical decision-making information for each employee's behavioral decisions. Let the staff decide whether we will continue to work hard in the next moment's work, or secretly take a break for a while; it is a cognition to complete the task, or to be too sloppy. So specifically, how does the emotion of leadership emotion the decision-making of employees' CWB?

Because the employee's CWB carried out by the individual, it is the behavioral response generated by the individual's subjective cognition. Therefore, the employee's CWB must have the individual's psychological measurement process. So what kind of psychological process does the influence of leadership emotions have on CWB? What is its internal mechanism? Van Kleef (2009) used the emerging sentiment, social information theory, to revise the emotional model by integrating emotional research. This research result opens a bright window for the research to explore the influence mechanism of leadership emotions on employees' CWB.

Because CWB is widespread in the workplace and has serious harm to the organization, managers must think about how to prevent the occurrence of CWB, reduce the occurrence of $\mathrm{CWB}$, and thus reduce the $\mathrm{CWB}$ of employees to harm organizations and the stakeholders. Therefore, it is particularly urgent to systematically exam the relationship between leadership emotion and employee CWB in Chinese context. How does leadership emotion affect employee CWB? What kind of psychological process is this influence formed? Is it possible to reduce 
employee CWB by affecting employees' own emotions? These issues need to be further exam through empirical research. Therefore, this study will deeply exam the influence of leadership emotions on CWBs, and try to use employee emotions as mediators to explore the influence mechanism of leadership emotions on employees' CWBs. And this study also considers whether the organizational justice that employees experience in organizations is It plays a regulatory role in order to further open the "black box" between leadership emotions and employee CWB from the perspective of employee psychological experience.

\section{Literature Review}

\subsection{EASI Model}

Affect can influence the interpersonal interaction between leaders and employees, and is the embodiment of the emotional social nature. On this basis, Van Kleef (2009) proposes a theoretical model of how leadership emotions affecting employee behavior-the Emotions As Social Information Model (EASI model). Leadership emotions can influence the work behavior of subordinate employees in two ways: Inferential process and affective reactions process, the reasoning path is that employees make certain reasoning based on the emotional expression of the leader and the feelings and attitudes behind their leadership emotions. The conclusion of reasoning affects the employee's work behavior; the affective reactions path refers to the emotional expression of the leader, which may directly affect the emotional response of the subordinate employees, and this emotional reaction process will directly affect the subordinate employees' own emotions and work behaviors [20]. The two paths and their impact on the work behavior of subordinate employees are shown in Figure 1. As an example of the reasoning process, a subordinate employee performs poorly in a work task, and his direct superiors express dissatisfaction with the negative emotions. Based on the emotions expressed by the leader, the employee may be aware of his or her own problems and make up for the lack of changes. Your own work behavior, and then there may be targeted measures to improve your weaknesses.

The relationship between leaders and employees is a typical relationship in the process of interpersonal interaction in an organization. Subordinate employees not only directly infected by the emotions of their superiors. Before the employees make

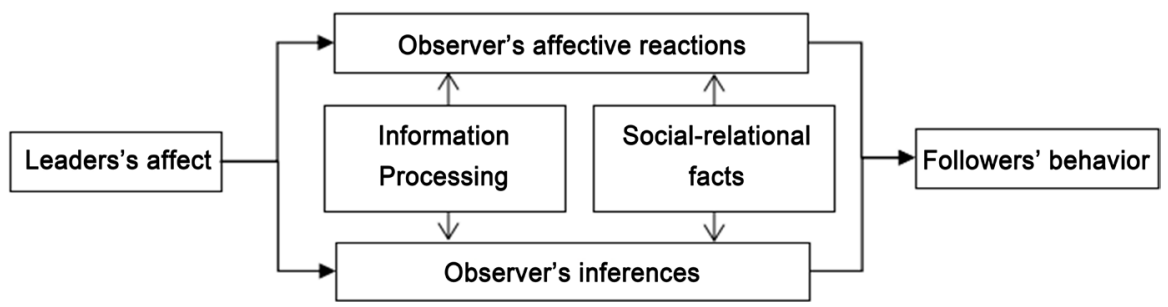

Figure 1. EASI: Van Kleef, G. A. (2009). How emotions regulate social life: The emotions as social information (EASI) model. Current Directions in Psychological Science, 18(3), 184-188. 
behavioral decisions, they also reason according to the emotional state of the leaders in the recent-period of time: the leader to express negative emotions caused by "I". Or is it to leader own problems, is it only to vent their personal feelings, when employees have an attitude of recognition of the internal fairness of the organization, employees will be more deeply reflective of "I", thereby reducing or reducing the frequency of their own CWB.

Based on the above theoretical basis and certain reasoning, this paper argues that EASI has certain possibility and feasibility in explaining the inherent relationship between leader's emotion and employees' CWB. Above all, we hypothesize the following:

Hypothesis 1a (H1a): Leadership positive emotions have a negative predictive effect on employees' CWBs.

Hypothesis $1 \mathrm{~b}(\mathrm{H} 1 \mathrm{~b})$ : leadership negative emotions have a negative predictive effect on employees' CWBs.

Hypothesis $2(\mathrm{H} 2)$ : Employees' own emotions have a mediating role between leadership emotions and employee CWB.

\subsection{Leader's Positive Emotion and Employee CWB}

\section{Organizational Justice}

Organizational Justice, this article focuses on the subjective feelings of fairness in organizations with employment relationships.

Organizational fairness has a broad sense of narrowness. Generally speaking, it refers to the objective conditions in the organization. For example, the external conditions such as the working environment, organizational system, and organizational procedures in the organization will make the employees in the organization feel fair, or the leaders in the organization will continuously improve these external objective conditions. In order to achieve the ultimate fair, but it is bigger. Narrow sense refers to the sense of organizational justice, and the subjective feelings of employees in the organization as to whether the objective conditions provided by the organization are fair. Of course, this definition has individual differences. The study in this paper uses a narrow interpretation, the purpose of which is to explore the regulatory role of the organizational sense of fairness perceived by the sample itself.

According to the theory of social exchange, employees strive to achieve their own commitment to the organization to obtain material and spiritual returns such as compensation and recognition. Research at home and abroad also shows that organizational fairness perception has an important impact on employee behavior. If employees feel that the organization provides more support to themselves, they will have a sense of responsibility to the organization, and they will work hard to return the organization and safeguard the interests of the organization. Bock et al. believe that social psychological factors are important factors influencing employees' CWB, especially the impact of organizational justice. Whether it is distribution fairness, procedural fairness or leadership fairness, when employees perceive a high level of organizational justice, em- 
ployees feel that their efforts will be rewarded, so they will work hard and reduce the occurrence of CWB. This reward organization; when employees feel low level of organizational fairness, employees will think that they are ignored by the organization, and the pay cannot be rewarded, so they will seek psychological balance by increasing CWB. Based on this study, the sense of organizational justice plays a regulatory role in the influence of leadership emotions on employees' CWB [70]. Based on the aforementioned arguments, we hypothesize the following:

Hypothesis 3 (H3): Organizational equity will moderate the relationship between leader's affect and employee CWBs.

\section{Study 1}

\subsection{Research Purposes}

Based on the analysis of the existing literature, Study 1 intends to analyze the leadership emotions, employee emotion, organizational justice and employee CWB from the following aspects:

1) In the real situation, explore the relationship between leadership emotions and employees' CWB;

2) In the real situation, explore the mediator role of employee emotions in the process of leadership emotions affecting employees' CWB;

3) In the real situation, it is necessary to explore whether the employee's sense of organizational justice plays a moderator role in the process of the leadership emotions influence the CWB.

\subsection{Research Ways}

\subsubsection{Participants}

The sample distribution is shown in Table 1. According to the gender division, there are 119 males, accounting for $42.5 \%$ of the total sample, and 161 females, accounting for $57.5 \%$ of the total sample. Female samples are more than male samples. According to the age group, the sample of employees aged $19-28$ is the largest, with a total of 135 , accounting for $48.2 \%$ of the total sample; the sample of employees aged 59 - 68 is the least, only 6 People, accounting for $2.1 \%$ of the total sample. The statistical results of education, working years, job category, business type and job competition in the position are shown in Table 1.

\subsubsection{Research Tools}

1) Employee positive emotion

The emotion scale selected of this research is the Chinese version of the PANAS scale revised by Huang, Yang, \& Ji (2003) after the analysis of the Chinese contextual applicability of the Positive And Negative Affect Scale (PANAS) compiled by Watson $\mathrm{D}$ et al. Measurement questions with good reliability in this study, Cronbach's $\alpha=0.877$.

2) The CWB scale for this study selected from the employee CWB scale compiled by David A. Jones (2009). The scale is divided into two dimensions: one dimension is pointing to the organization $(\mathrm{CWB}-\mathrm{O})$ and the other dimension is 
Table 1. Sample distribution $(\mathrm{n}=280)$.

\begin{tabular}{|c|c|c|c|}
\hline Demographic Variables & Sample Characteristics & Frequency & Percentage \\
\hline \multirow{2}{*}{ SEX } & Male & 119 & 42.5 \\
\hline & Female & 161 & 57.5 \\
\hline \multirow{5}{*}{ AGE } & 59 - 68 years old & 6 & 2.1 \\
\hline & $49-58$ years old & 24 & 8.6 \\
\hline & 39 - 48 years old & 39 & 13.9 \\
\hline & 29 - 38 years old & 76 & 27.1 \\
\hline & $19-28$ years old & 135 & 48.2 \\
\hline \multirow{4}{*}{ Education } & Master and above & 43 & 15.4 \\
\hline & Junior college/undergraduate & 198 & 70.7 \\
\hline & High school & 30 & 10.7 \\
\hline & Specialist & 9 & 3.2 \\
\hline \multirow{5}{*}{ Working years } & 1 year or less & 34 & 12.1 \\
\hline & $1-3$ years & 60 & 21.4 \\
\hline & $4-6$ years & 70 & 25 \\
\hline & $7-10$ years & 55 & 19.6 \\
\hline & 11 years and above & 61 & 21.8 \\
\hline \multirow{4}{*}{ Job category } & Top management & 9 & 3.2 \\
\hline & Middle manager & 42 & 15 \\
\hline & Grassroots manager & 97 & 34.6 \\
\hline & employee & 132 & 47.1 \\
\hline \multirow{4}{*}{ Business Type } & Foreign-invested enterprise & 25 & 8.9 \\
\hline & State-owned enterprise & 125 & 44.6 \\
\hline & Private enterprise & 83 & 29.6 \\
\hline & Other & 47 & 16.8 \\
\hline \multirow{4}{*}{$\begin{array}{l}\text { Job competition in the } \\
\text { position }\end{array}$} & no job competition & 48 & 17.1 \\
\hline & little work competition & 118 & 42.1 \\
\hline & strong work competition & 77 & 27.5 \\
\hline & very strong job competition & 37 & 13.2 \\
\hline
\end{tabular}

directed at his immediate superior (CWB-S). Measurement questions with good reliability in this study, Cronbach's $\alpha=0.877$, Cronbach's $\alpha=0.935$.

3) Organizational justice

Liu \& Long (2003) compiled a scale of organizational fairness. The original scale includes two dimensions: procedural fairness and leadership fairness. The scale has recognized by domestic scholars since its development, and possess higher reliability and validity. Measurement questions with good reliability in this study, Cronbach's $\alpha=0.94$.

4) Demographic information collection scale 
5) Data Analysis tool

In this study, two statistical analysis softwares, Spss22.0 and PROCESS, used as the analysis tools for the data collected. Spss22.0 used for descriptive statistical analysis, reliability analysis, correlation analysis, and regression analysis, PROCESS used for structural equation modeling.

\subsection{Research Process}

This study was a one-time cross-sectional study, and the questionnaire distributed to employee working in different organizations by their Superior or HR from November to December 2018 using the principle of convenient sampling. The electronic version of questionnaire completed by the software of wenjuanxing and distributed via WeChat. The questionnaire has a total of 72 items, of which the leadership positive emotion scale includes 10 items, the employee emotion scale includes 20 items, the employee CWB scale includes 13 items, and the organizational fairness scale includes 22 items. The employee background information includes 7 items. The samples are from 16 companies in Guangzhou, Jinan, Changsha, etc., including 7 state-owned enterprises, 4 foreign-funded enterprises, and 5 private enterprises. The industries involved include banking, insurance, power systems, real estate, legal consulting, and management consulting., fast-moving, Internet and other fields. A total of 330 questionnaires were distributed, including 190 paper-based questionnaires and 140 electronic questionnaires. 302 questionnaires were collected, including 163 paper-based questionnaires and 139 electronic questionnaires. The collected questionnaires classified as invalid questionnaires: 1) more than two-thirds of the questionnaires are blank; 2) all answers are the same for the entire questionnaire. After screening, there were 280 valid questionnaires, including 155 paper-based questionnaires and 125 electronic questionnaires. The effective questionnaires accounted for $92.7 \%$.

The questionnaire first informs the subject of the research and the privacy protection clause, and then let the participants recall the process of interpersonal interaction with their immediate superiors in the work experience of the most recent month through the emotional awakening of memories, and then the perceived leadership through self-evaluation. Questionnaire self-assessment of 1 - 5 points in leadership positive emotions, self-emotions, organizational justice, and CWB. Finally fill in the demographic information.

\subsection{Result}

\subsubsection{Common Method Variance and Bias}

Collecting data using self-reporting methods may have a common method bias. Therefore, this study used the single factor test. The results showed that there were 16 factors with eigenvalues greater than 1 , and the first factor explained a variation of $21.336 \%$, less than $40 \%$ of the critical criteria, indicating that there is no serious common method bias in this study. 


\subsubsection{Related Analysis}

1) Correlation analysis between leadership emotions and employee CWB

As can be seen from Table 2, there is a significant negative correlation between the positive emotion expressed by the leader and two dimensions of CWB including the employee's CWB pointing to the superior(CWB-S) $(\mathrm{r}=-0.436, p$ $<0.01)$ and the employee's CWB pointing to the organization $(\mathrm{CWB}-\mathrm{O})(\mathrm{r}=$ $-0.286, p<0.01)$.

2) Correlation analysis between leadership positive emotions and employee emotions

From Table 2, it can intuitively judge that there is a significant positive correlation between the positive emotions expressed by the leaders and the positive emotions of the employees $(r=0.673, p<0.01)$; and there is a significant negative correlation between the positive emotions expressed by the leaders and the negative emotions of the employees $(r=-0.237, p<0.01)$.

3) Correlation analysis between employee emotions and employee CWB

From Table 2, it can intuitively judge that there is a negative correlation between employee emotions and employee CWB. Among them, there is a significant negative correlation between the positive emotions of employees and both the CWB of employees pointing to superiors (CWB-S) $(\mathrm{r}=-0.565, p<0.01)$ and the CWB of employees pointing to organizations (CWB-O) $(\mathrm{r}=-0.457, p<$ $0.01)$; There is a significant positive correlation between the negative emotions of employees and both the CWB-S $(\mathrm{r}=0.396, p<0.01)$ and the CWB-O $(\mathrm{r}=$ $0.333, p<0.01)$.

4) Correlation analysis among organizational justice, leadership positive emotions, employee sentiment and employee CWB

From Table 2, it can intuitively judge that there is a positive correlation between organizational justice, leadership positive emotions, and employee emotions. Specifically, the two dimensions of organizational justice, procedural fairness $(\mathrm{r}=$

Table 2. Related analysis.

\begin{tabular}{|c|c|c|c|c|c|c|c|c|}
\hline Group & $\mathrm{M}$ & $S D$ & 1 & 2 & 3 & 4 & 5 & 6 \\
\hline $\begin{array}{l}\text { 1) Leadership positive } \\
\text { emotion }\end{array}$ & 3.368 & 0.691 & 1 & & & & & \\
\hline $\begin{array}{l}\text { 2) Employee positive } \\
\text { emotion }\end{array}$ & 3.297 & 0.693 & $0.673^{\star *}$ & 1 & & & & \\
\hline $\begin{array}{l}\text { 3) employee negative } \\
\text { emotion }\end{array}$ & 2.636 & 0.701 & $-0.237^{\star *}$ & $-0.291^{\star *}$ & 1 & & & \\
\hline 4) procedural justice & 3.340 & 0.836 & $0.167^{* *}$ & $0.267^{* *}$ & 00.002 & 1 & & \\
\hline 5) Leadership justice & 3.497 & 0.900 & $0.200^{* *}$ & $0.260^{* *}$ & $-0.149^{*}$ & $0.632^{* *}$ & 1 & \\
\hline $\begin{array}{l}\text { 6) points to the } \\
\text { organization CWB }\end{array}$ & 2.104 & 0.741 & $-0.286^{\star \star}$ & $-0.457^{\star \star}$ & $0.333^{\star *}$ & $-0.207^{\star \star}$ & $-0.203^{\star *}$ & 1 \\
\hline $\begin{array}{l}\text { 7) points to the } \\
\text { superior CWB }\end{array}$ & 1.876 & 0.805 & $-0.436^{\star *}$ & $-0.565^{\star \star}$ & $0.396^{* *}$ & $-0.176^{\star *}$ & $-0.313^{\star *}$ & $0.648^{\star *}$ \\
\hline
\end{tabular}

Note: ${ }^{* *}, p<0.01 ; *, p<0.05$. 
$0.167, p<0.01)$ and leadership fairness $(\mathrm{r}=0.200, p<0.01)$, are significantly positively correlated with the leadership positive emotions; the two dimensions of organizational justice, procedural fairness $(r=0.267, p<0.01)$ and leadership fairness $(\mathrm{r}=0.260, p<0.01$ ), are significantly positively correlated with the dimension of employee positive emotional.

It can find from Table 2 that there is a significant negative correlation between organizational justice and employees' CWB variables. There is a significant negative correlation between the two dimensions of organizational justice and the two dimensions of employee's CWB ( $\mathrm{r}_{\text {procedural fairness-CWB-s }}=0.167, p<$ $0.01 ; \mathrm{r}_{\text {leadership fairness-CWB-s }}=0.313, p<0.01 ; \mathrm{r}_{\text {procedural fairness-CWB-O }}=0.207, p<0.01$; $\left.\mathrm{r}_{\text {leadership fairness-CWB-S }}=0.203, p<0.01\right)$.

\subsubsection{Regression Analysis}

1) Regression analysis of leadership emotions on CWB

The results of data analysis show that leadership positive emotions can significantly negatively predict the CWB-S $(\beta=-0.283, p<0.001)$, that is, the higher the positive level of leadership emotion felt by employees, the employees do the less CWB that points to the superior. Leadership positive emotions can significantly predict the CWB-O $(\beta=-0.177, p<0.01)$, that is, the higher the positive level of leadership emotion felt by employees, the employees do the less CWB that points to the organization. The hypothesis 1 is verified.

2) Regression analysis of leadership emotions on employee emotions

The results of data analysis show that positive leadership emotions significantly affect the positive emotions of employees. Leadership positive emotions can significantly positively predict employee positive emotions $(\beta=0.581, p<$ 0.001 ), that is, the higher the positive level of leadership emotion perceived by employees, the more positive emotion of employee. The predictive effect of positive emotions on employees' negative emotions was not significant $(\beta=-0.022$, $p>0.05)$.

\subsubsection{Analysis of the Mediating Effect of Employee Emotion}

Wen \& Ye (2014) integrated Baron \& Kenny's partial mediation test methods and Judd \& Kenny's complete mediation test methods, and proposed a mediation effect test procedure, which is widely used by scholars. This study will also test using the mediating effect test procedure proposed by Wen.

The results of stepwise multiple regression analysis are shown in Table 3 to Table 4, in which gender, age, education, seniority, job category, business type, and post competition are the control variables, leadership positive emotion is the independent variable (IV), the employee positive emotion is the mediator variable, the CWB-O and CWB-S are the dependent variables (DV).

1) Analysis of the mediating effect of positive emotions of employees in the process of leadership positive emotions affecting employees' CWB-O

From the result of multivariate stepwise regression analysis, the control variables can explain the $8.7 \%$ variation of the dependent variable $(p<0.01)$. The 
Table 3. The mediating effect of employees' positive emotions in the process of leading positive emotions affecting CWB-O.

\begin{tabular}{|c|c|c|c|c|c|c|c|c|c|}
\hline \multirow{2}{*}{ Predictor } & \multicolumn{3}{|c|}{ Model 0 CWB-O } & \multicolumn{3}{|c|}{ Model 1 Employee positive emotions } & \multicolumn{3}{|c|}{ Model 2 CWB-O } \\
\hline & $\beta$ & SE & $\mathrm{t}$ & $\beta$ & SE & $\mathrm{t}$ & $\beta$ & SE & $\mathrm{t}$ \\
\hline SEX & -0.052 & 0.086 & -0.601 & -0.111 & 0.062 & -1.79 & -0.108 & 0.081 & -1.324 \\
\hline AGE & 0.049 & 0.065 & 0.755 & -0.027 & 0.047 & -0.566 & 0.036 & 0.061 & 0.59 \\
\hline Education & 0.179 & 0.078 & $2.303^{*}$ & -0.076 & 0.056 & -1.363 & 0.141 & 0.073 & $1.933^{*}$ \\
\hline Working years & -0.046 & 0.058 & -0.784 & -0.004 & 0.042 & -0.096 & -0.048 & 0.055 & -0.876 \\
\hline Job category & 0.016 & 0.058 & 0.284 & 0.057 & 0.042 & 1.377 & 0.045 & 0.054 & 0.831 \\
\hline Business Type & -0.12 & 0.052 & $-2.297^{*}$ & 0.065 & 0.038 & 1.717 & -0.088 & 0.049 & -1.787 \\
\hline $\begin{array}{l}\text { Job competition } \\
\text { in the position }\end{array}$ & -0.125 & 0.051 & $-2.433^{*}$ & 0.134 & 0.037 & $3.618^{* *}$ & -0.058 & 0.049 & -1.183 \\
\hline Leadership positive emotion & -0.258 & 0.066 & $-3.888^{* *}$ & 0.61 & 0.048 & $12.794^{* *}$ & 0.047 & 0.079 & 0.602 \\
\hline Employee positive emotions & & & & & & & -0.5 & 0.079 & $-6.332^{* *}$ \\
\hline $\mathrm{R}^{2}$ & & 0.135 & & & 0.491 & & & 0.247 & \\
\hline$\Delta \mathrm{R}^{2}$ & & 0.135 & & & 0.491 & & & 0.112 & \\
\hline $\mathrm{F}$ & & $5.288^{\star *}$ & & & $32.644^{* *}$ & & & $9.834^{* *}$ & \\
\hline
\end{tabular}

Note: ${ }^{* *}, p<0.01 ; *, p<0.05$.

Table 4. The mediating effect of employees' positive emotions in the process of leading positive emotions affecting CWB-S.

\begin{tabular}{|c|c|c|c|c|c|c|c|c|c|}
\hline \multirow{2}{*}{ Predictor } & \multicolumn{3}{|c|}{ Model 0 CWB-S } & \multicolumn{3}{|c|}{ Model 1 Employee positive emotions } & \multicolumn{3}{|c|}{ Model 2 CWB-S } \\
\hline & $\beta$ & SE & $\mathrm{t}$ & $\beta$ & SE & $\mathrm{t}$ & $\beta$ & SE & $\mathrm{t}$ \\
\hline SEX & -0.026 & 0.088 & -0.299 & -0.111 & 0.062 & -1.79 & -0.087 & 0.082 & -1.062 \\
\hline AGE & 0.058 & 0.067 & 0.869 & -0.027 & 0.047 & -0.566 & 0.044 & 0.062 & 0.704 \\
\hline Education & 0.193 & 0.08 & $2.428^{*}$ & -0.076 & 0.056 & -1.363 & 0.152 & 0.074 & $2.052^{*}$ \\
\hline Working years & -0.036 & 0.06 & -0.598 & -0.004 & 0.042 & -0.096 & -0.038 & 0.055 & -0.686 \\
\hline Job category & -0.063 & 0.059 & -1.069 & 0.057 & 0.042 & 1.377 & -0.032 & 0.055 & -0.582 \\
\hline Business Type & -0.092 & 0.054 & -1.714 & 0.065 & 0.038 & 1.717 & -0.056 & 0.05 & -1.133 \\
\hline Job competition in the position & -0.142 & 0.053 & $-2.701^{\star \star}$ & 0.134 & 0.037 & $3.618^{* *}$ & -0.069 & 0.05 & -1.383 \\
\hline Leadership positive emotion & -0.443 & 0.068 & $-6.517^{\star *}$ & 0.61 & 0.048 & $12.794^{* *}$ & -0.109 & 0.08 & -1.364 \\
\hline Employee positive emotions & & & & & & & -0.548 & 0.08 & $-6.844^{* *}$ \\
\hline $\mathrm{R}^{2}$ & & 0.232 & & & 0.491 & & & 0.346 & \\
\hline$\Delta \mathrm{R}^{2}$ & & 0.232 & & & 0.491 & & & 0.114 & \\
\hline $\mathrm{F}$ & & $10.243^{* *}$ & & & $32.644^{\star *}$ & & & $15.849^{* *}$ & \\
\hline
\end{tabular}

Note: ${ }^{* *}, p<0.01 ;^{*}, p<0.05$.

level of interpretation of the outcome variable was improved after the addition of the predictor variable $\left(\Delta \mathrm{R}^{2}=0.048, p<0.01\right)$. After adding positive emotions of employee as the mediators, the explanatory amount was further increased $\left(\Delta \mathrm{R}^{2}=0.112, p<0.01\right)$. Hypothesis 2 partially verified.

According to the results, the predictive effect of leadership positive emotion 
(IV) on the CWB-O (DV) is significant, indicating that employees with higher scores on leadership positive emotion show less CWB towards the organization. The IV has a significant predictive effect on the mediator variable, indicating that the more active emotion expressed by leader, the more active employee's emotions.

In addition, when the positive emotions of the leadership and the positive emotions of the employees put into the structural equation to predict the CWB-O of the employees, the predictive effect of the positive emotion of employee is significant, but the predictive effect of the leadership positive emotion becomes insignificant. It explains that the more leadership positive emotion perceived by employees, they feel more positive emotions, which further influence their CWBs directed at the organization, and proving that the employees' positive emotion acts as a complete mediator between leadership positive emotion and the CWB-O of employee. The model of the mediation effect at the process of leadership positive emotion affecting the employee CWB-O is shown in Figure 2.

2) Analysis of the mediating effect of positive emotions of employees in the process of leadership positive emotions affecting employees' CWB pointing to superiors (CWB-S)

From the multivariate stepwise regression analysis, the control variables can explain the variation of the dependent variable $11.2 \%(p<0.01)$. The level of interpretation of the DV improved after the addition of leadership positive emotion (IV), and the $12 \%$ variation of the DV was explained $(p<0.01)$. After adding employee positive emotion to the mediators, the explanatory amount was further increased $\left(\Delta \mathrm{R}^{2}=0.114, p<0.01\right)$. Hypothesis 2 partially verified.

According to the results, the predictive effect of IV on the CWB-S is significant, indicating that the employee with higher positive emotion scores about leader show less CWB-S. The IV has a significant predictive effect on the mediator variable, indicating that the more active leadership emotion felt by employee, the more active emotion of employee felt.

In addition, when the positive emotions of the leadership and the positive emotions of the employees put into the structural equation to predict the CWB-S of the employees, the predictive effect of the positive emotions of the employees is significant, but the predictive effect of the positive emotions of the leaders

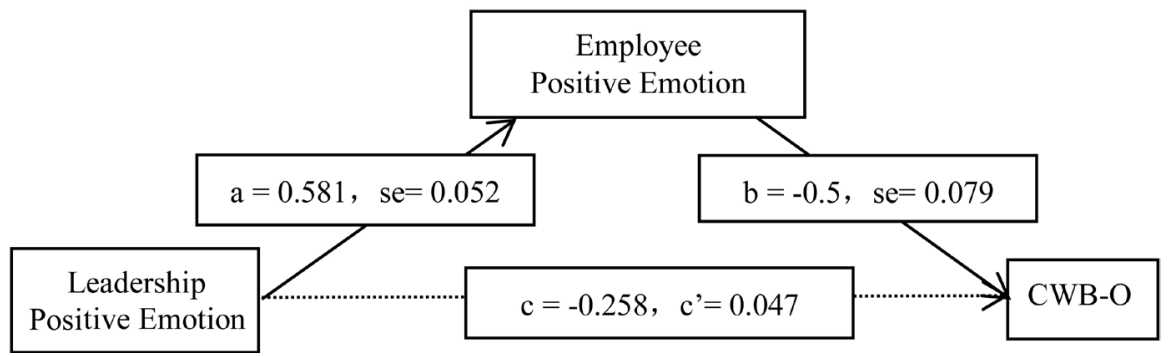

Figure 2. The mediating effect of employees' positive emotions in the process of leading positive emotions affecting CWB-O. 
becomes insignificant. It explains that the leadership positive emotional stimuli improved positive emotion degree of the employees themselves, which further affect the CWB-S of the employees. It means that the positive emotions of the employees have a complete mediating role at the process of leadership positive emotion affecting the employee's CWB-S. The model of the mediation effect at the process of leadership positive emotion affecting the employee CWB-S is shown in Figure 3.

\subsubsection{Analysis of the Moderating Effect of Organizational Justice}

According to the theoretical hypothesis and the results of relevant analysis, the sense of organizational justice perceived by employees and its various sub-dimensions play a moderating role in the process of leadership positive emotion affecting employees' CWBs that mediated by employee emotions. There is a significant positive correlation between employees' perception of procedural fairness and leadership positive emotion scores, and a significant positive correlation with employees' positive emotions, and a significant negative correlation with employees' CWBs directed at organizations and employees' CWBs directed at superiors. Employees' perception of leadership justice significantly negatively correlated with leadership dominant negative emotion scores, positively correlated with leadership positive emotion scores, significantly positively correlated with employee positive emotions, and negatively correlated with employee negative emotions. There is a significant negative correlation between the organization's CWB and the CWB of employees pointing to superiors. Therefore, according to the results of the mediation effect analysis, the positive emotions of the leadership influenced by the positive emotions of the employees, the CWBs of the employees pointing to the organization, and the CWBs directed to the superiors.

According to the result, we just found that the leadership justice can play a moderator role in the process of leadership positive emotion affecting CWB-S through employee's positive emotions.

The test carried out by the moderator-mediator model test method proposed by Wen \& Ye (2014). It was found that the positive emotion of leadership (X) had a significant effect on the employee's CWB-S (Y) $\left(c_{1}=-1.030, t=-4.456, p\right.$ $<0.01$ ), the interaction (UX) between the leadership positive emotion (X) and the leadership justice $(\mathrm{U})$ has a significant effect on the employee's CWB-S (Y) $\left(c_{3}\right.$

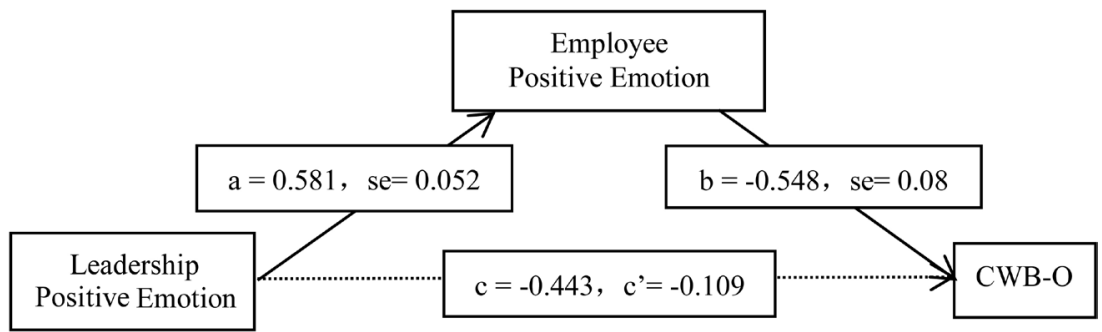

Figure 3. The mediating effect of employees' positive emotions in the process of leading positive emotions affecting CWB-S. 
$=0.191, \mathrm{t}=2.907, p<0.01)$. The positive emotion of leadership $(\mathrm{X})$ have significant effect on employees' positive emotions $(\mathrm{M})\left(\mathrm{a}_{1}=0.531, \mathrm{t}=3.284, p<0.01\right)$. The interactions (UX) between leadership positive emotions (X) and leadership justice $(U)$ has no significant effect on employee positive emotion $(M)\left(a_{3}=\right.$ $0.036, \mathrm{t}=0.749, p>0.05)$. Employee positive emotion $(\mathrm{M})$ had a significant effect on employee's CWB-S $(\mathrm{Y})\left(\mathrm{b}_{1}=-1.123, \mathrm{t}=-5.611, p<0.01\right)$, the interaction (UM) between employee positive emotion (M) and leadership justice (U) has a significant effect on the employee's CWB-S $(\mathrm{Y})\left(\mathrm{b}_{2}=0.187, \mathrm{t}=3.420, p<0.01\right)$. That is, the process of leadership positive affects the employee's CWB-S emotions through employees' positive emotions moderated by the sense of leadership justice perceived by the employees in the organization.

In addition, the Variance Inflation Factor (VIF) of all predictive variables in this study were low than 1.5 , indicating that there is no multi-collinearity problem. In order to explain the essence of the interaction between leadership positive emotions and employee leadership justice, we perform a simple slope test and draw a simple effect analysis chart.

Figure 4 shows that leadership justice moderates the relationship between leadership positive emotion and employee CWB-S because this relationship is different in the presence of high (+1SD) and low (-1SD) leadership justice. The results show that low leadership justice group member's CWB-S has been significant influenced by leadership positive emotion $\left(\beta_{\text {simple }}=-0.542, \mathrm{t}=-6.491\right.$, $p<0.01)$ compared with high justice group member. For high-group employees who feel high sense of leadership justice, the leadership positive emotion's predictive effect is weakened $\left(\beta_{\text {simple }}=-0.187, \mathrm{t}=-1.991, p<0.05 ; \beta_{\text {simple }}=-0.542\right.$ weakened to $\left.B_{\text {simple }}=-0.187\right)$. Hypothesis 3 partially verified.

The process of positive emotions of leaders affects the CWB-S of employees through their positive emotions moderated by the sense of leadership that employees perceive in the organization. For employees with low leadership justice, the direct effect of leadership positive emotions on employees' CWB-S is significant, index $=-0.255$, Boot $\mathrm{SE}=0.089,95 \%$ confidence interval is $[-0.431,-0.080]$; the

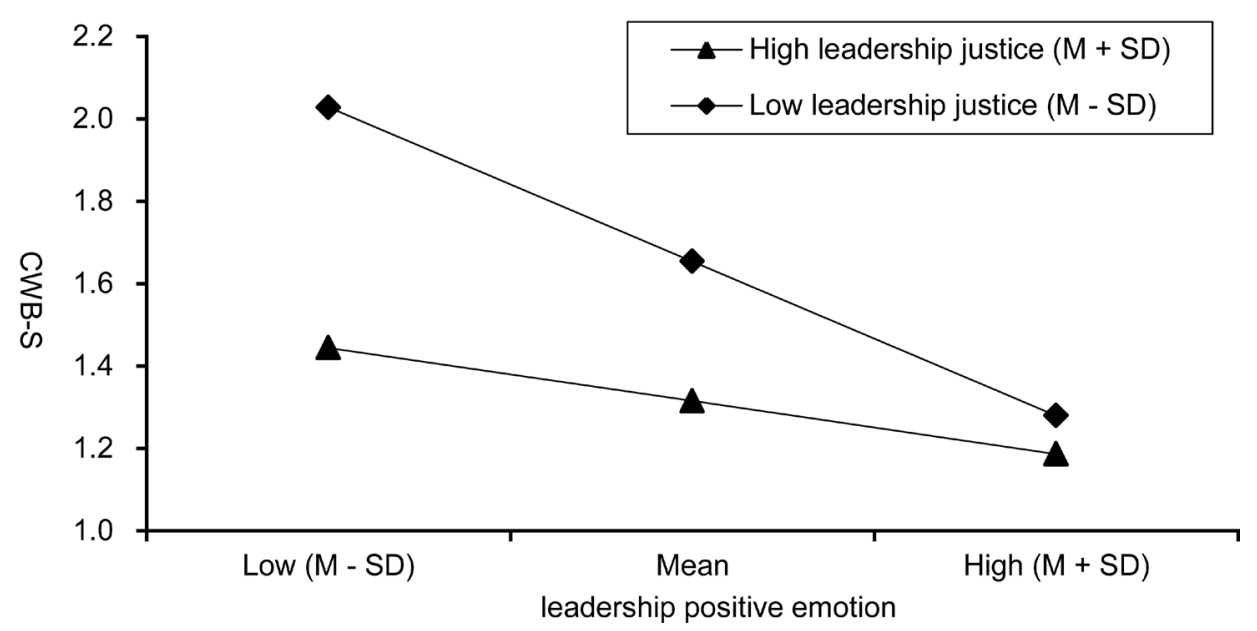

Figure 4. The moderating effect of leadership justice. 
direct effect is not significant for employees with higher justice, index $=0.120$, Boot $\mathrm{SE}=0.099,95 \%$ confidence interval is $[-0.076,0.317]$. Model structure Figure 5 is as follows.

\subsection{Discussion}

\subsubsection{Analysis of the Results of Leadership Emotions Affecting Employees' CWB}

In discussing the impact of leadership emotions on employee CWB, this study proposes that $\mathrm{H} 1$ leadership positive emotions have a negative predictive effect on employee CWB. After regression analysis, the assumption $\mathrm{H} 1$ that has a significant negative impact on employees' CWB is confirmed. The research results show that the positive degree of leadership emotion perceived by employees is an important factor in determining the frequency of employees' CWB.

Employees adjust their behavior according to the emotional state expressed by their direct superiors. When the superior express their emotional state in the work scene and those emotional state present positive and positive characteristics such as work commitment and enthusiasm, the employees tend to reduce the frequency of CWBs (including CWB-S and CWB-O). This conclusion is consistent with the findings of most scholars that employees are more inclined to adopt the same positive attitude, and then work more actively when the environmental information received by employees is positive. Combining China's unique cultural and emotions background, that is, social information theory, the positive emotional information displayed by leaders in the work scene conveys positive to employees. Positive signals represent complex and positive information, such as safety, dedication, and recognition of their own efforts. They provide the most important information input for employees to make positive decisions and behaviors. Due to the input of information that leader's positive emotion, which makes employees full of hope for work and personal prospects, thus reducing individual CWB.

\subsubsection{Analysis of the Results of the Mediating Effect of Employee Sentiment} In analysis the impact of employee emotion on employee CWB, this study proposes hypothesis 2: Employees' own emotions have a mediating effect between

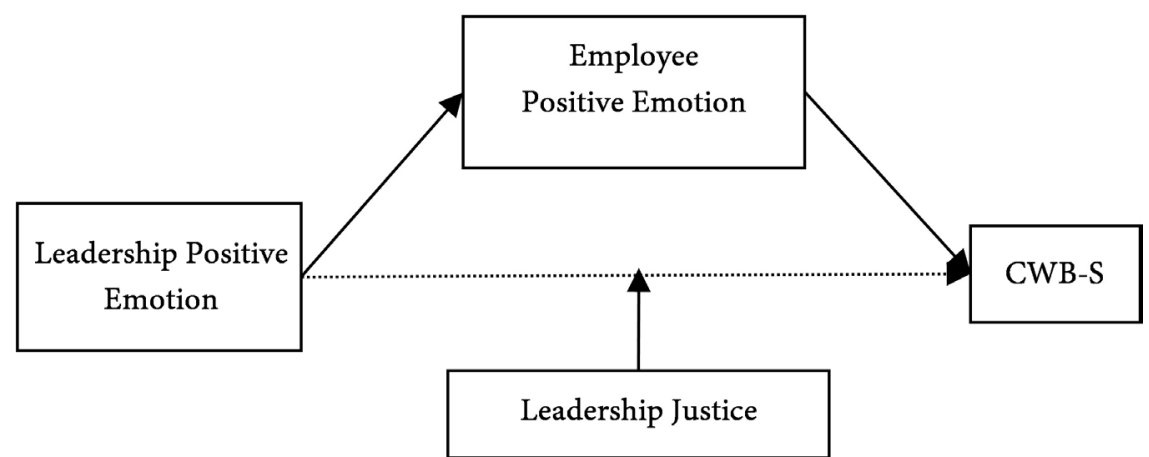

Figure 5. Structure of a regulated intermediary model that influences the positive emotions of employees to the superiors. 
leadership positive emotions and employee CWB. After the mediation effect analysis, hypothesis 2 is only partially confirmed.

The empirical analysis of this study shows that employee sentiment plays a full mediating role in the process of leading positive emotions affecting employees' $\mathrm{CWB}$, and verifies hypothesis $\mathrm{H} 2$. The negative impact of leadership emotions on employees' CWB is to influence the employee's personal emotions first, and then negatively affect employees' CWB. Leader's positive emotions felt by the employees are processed, analyzed and judged by the employees, and let employee forming their own emotions or changing the original emotional state of the employees. The emotional state of the employees newly formed or changed is positive or negative. It implies that the overall evaluation of the state of leadership emotions felt by employees is positive or negative, and then employee forms the decision of CWB that to reduce CWB, or Increase the frequency of CWB in order to seek their own maximum interests and satisfaction. These interests and satisfactions are more likely related to venting personal emotions, seeking fairness in work input and output, or pursuing personal career prospects.

Consistent with previous studies, the positive emotions of employees play a mediating role in the process of leadership positive emotion affecting employees' CWB-O and CWB-S, while the mediation effect of employees' negative emotions is not significant. The reason may be that the leaders are full of positive emotions of work enthusiasm, let the employees feel the warmth and hopeful, and stimulate the positive emotions of the employees. Therefore, the employees have made the decision to reduce the CWB and put more into their Work. For the negative emotions of employees, the positive emotions conveyed by the leaders have no significant influence on it, so it could not act as a mediator at the process of affecting the CWB of employees. Based on the theory of emotions as social information, we can easily find that the leaders convey positive emotions do not always have an inhibitory effect on employees' negative emotions, and sometimes even reverse the negative emotions of employees. There may be potential moderator that affects the relationship between leadership positive emotion and negative emotion of employees.

\subsubsection{Analysis of the Results of the Mediating Moderating Effect of Organizational Justice}

The empirical analysis of this study shows that the sense of organizational justice felt by employees plays a moderator role in the model of employee CWB influenced by employee emotions, and partially verifies hypothesis 3 .

Specifically, the sense of leadership justice plays a significant moderator role in the process of leadership positive emotions affecting employees' CWB-S though employee emotion. It is temporary, the leadership has a high degree of equal treatment for employees, and there is a sense of belonging within the organization, so its own positive emotions are less affected by the positive emotions of the leaders, and then the fluctuations of their CWB-S also less. However, employees with low scores on leadership fairness lack a sense of identity for their 
superiors and lack a sense of belonging to their organizations. The positive emotions conveyed by direct leadership have a greater impact on their work status and are more susceptible to positive emotional fluctuations. The positive emotions of leaders can determine the positive level of employee's emotions and the Influence becomes a greater extent, which in turn affects their performance and CWB. According to the results of data analysis, we can easily find that the direct effect of the mediator model is significant only under the moderating of leadership justice, and when there is no leadership justice to play a moderator role, the leadership positive emotion's effect are based on the positive emotions of employees. The model of leadership positive emotion affecting the employee's CWB-S is a complete intermediary model. That is to say, in the group with low leadership fairness, the employee's CWB-S not only influenced by the indirect effect of the employee's own positive emotions, but also influenced by the direct effect of the leadership positive emotion. The lower sense of leadership justice will increase the effectiveness of direct influence of leading positive emotions. According to emotions as social information theory analysis, it is find that the potential cause of this phenomenon is that for the employee groups with higher leadership fairness, their own emotional and behavioral decisions is based on both the infection path and inferred path for the leadership positive emotion information. The influence of leadership positive emotions is a comprehensive product of employees' rational decision-making and perceptual decision-making. For groups with low leadership fairness, their own positive emotions and behavioral decisions are more likely to follow the trajectory of the emotional infection path when they influenced by the leadership positive feelings they feel. They have higher possibility to deal with leadership positive emotional information just in the form of the most direct infection, but not deep analysis, so that they generate the same positive emotions compared with their leader, and reduce the emotional CWB that opposite to the type of leadership positive emotions.

\section{Study 2}

\subsection{Research Purpose}

Study 1 verified the moderator role of leadership justice in the process of the leader's positive emotion influencing employee's CWB-S via their positive emotions by the questionnaire, but whether this conclusion be established in the laboratory context or not? Study 2 will test the results of Study 1 through experiments. In the case of controlling employees' sense of leadership fairness, participates whether will be more active when they are facing leadership positive emotional events or not? Whether they will tend to reduce the decision of CWB-S. Specifically, it includes two research purposes as following:

1) Whether the mediating effect of employees' positive emotions still established in the laboratory context;

2) Whether the moderator-mediator effect of the employee's leadership justice 
still established in the laboratory context.

\subsection{Research Ways}

\subsubsection{Participants}

Undergraduate and postgraduate students selected as research subjects, and the experimental recruitment information published on the campus information platform of two higher universities in Guangzhou of China. There are 128 students volunteered to participate in the experiment, and 114 of them were effectively completed. The average age of the subjects was 23.19 years old $(\mathrm{SD}=2.72)$, including 36 males and 78 females.

According to Spector et al (2006), in order to reduce the social appreciating effect of the dependent variable (CWB-S) concerning with social sensitivity, this study has collected the limited of demographic information, and thus improved the authenticity of the research data. The consideration of the anonymity of the study, only the demographic information of the age and gender of the subjects collected in this study. All subjects signed informed consent before the experiment, and the mood was normal. There was no history of neurological or mental illness. They had not participated in relevant experiments before. All the subjects received 5 yuan of experimental reward after the end of the experiment.

\subsubsection{Research Tools}

1) Situational material

The editors of the starting materials for the organization's sense of fairness mainly refer to the Chinese version revised by $\mathrm{Xu}$ (2015) was basis of experimental materials compiled by Kennedy et al. Contains one unfair start-up materials and a neutral starter. Each organization's sense of fairness situation accompanied by a corresponding question, asking the participants to judge the fairness of the situation ( $1-7$ point, 1 point means that the degree of justice presented in the material is very fair, 7 points the degree of justice indicating the background of the material is very unfair).

The initiation material for leadership emotion in this study compiled based on the emotionally induced research paradigm. Each leadership emotional priming material contains a description of the task context and an emotional index of the image. The material followed by a corresponding question asking the participant to judge the leadership emotion presented by the material based on the material information ( 1 - 7 point, 1 point means that the leadership emotion presented in the material is very negative, and 7 point indicates that the leadership emotion presented in the material is very positive).

2) Employee positive emotion

Same to study 1 .

3) CWB

Same to study 1 .

4) Demographic information collection scale

5) Data Analysis tool 
Same to study 1 .

\subsection{Research Process}

1) Experimental design

Study 2 was 2 (Leader Unfair Start, Neutral Start) X2 (Leader Positive Emotion, Leadership Neutral Emotion). The experimental design conducted, in which the independent variables were leadership fairness and leadership positive emotion, and the dependent variable was the direction of the subjects. The behavioral tendency of the superior $\mathrm{CWB}$, the mediator variable is the self-positive emotion of the subject.

2) Implementation process

The second study was a collective test. The subjects were undergraduate students or postgraduates from two higher universities in Guangzhou. There are 128 people participated in the test, and 114 subjects completed the test ( 36 males and 78 females), the average age. 23.19 years old $(S D=2.72)$.

With the help of the experimental assistant, the subjects tested in the classroom and the specific procedures were as follows:

First, before accepting the experimental treatment, the participants asked to fill in the informed consent and basic information of demographics. Secondly, the subjects randomly divided into 4 groups, 3 experimental groups, and 1 control group, which in turn accepted the leader's unfair situation start. Materials and leadership positive emotions start materials. Finally, the participants give a positive emotional scale and a counter-production behavior scale pointing to the superiors to test the mediator variables and dependent variables. In order to prevent the participants from discussing each other during the experiment or other confusion, the results of the study adversely affected. Three psychology graduate students invited to serve as the main interviewer and experimental assistants of the experiment. Before the official start of the experiment, the main interviewer will explain to the participants the purpose of the experiment and a number of requirements at the beginning of experiment. If the subject has any questions, they can ask help for the main interviewer and the experimental assistant in time, in order to avoid mutual communication.

\subsection{Results}

\subsubsection{Operational Effectiveness Test}

1) Leadership positive emotional situation operational effectiveness test

In the formal experiment, the leaders of the positive emotion group and the leadership neutral emotion group judged the degree of leadership positive emotion perceived from the experimental materials, and the results are shown in Table 5.

2) Organizational procedures unfair situation operational effectiveness test

In the formal experiment, the leaders of the unfair group and the fair group judged the unfairness of the presented situation in the experimental materials, and the results are shown in Table 6. 


\subsubsection{The Influence of Leadership Positive Emotions on Employees' CWB Tendency}

After the implementation of the operational situation, the analyzed results about the scores of the experimental group and the control group on the CWB-S are as Table 7.

The scores of the participants in the different leadership emotion operational group on the CWB-S scale are shown in Table 7. The t-test results show that the CWB-S scores of the leader positive emotion start-up group significantly lower than the leadership neutral emotion start-up group. The results show that participants in the leadership positive emotional situation are more inclined to reduce the implementation of CWB-S than those who belonging leadership neutral emotional situation, so that $\mathrm{H} 1$ is confirmed in the laboratory context.

\subsubsection{Analysis of the Mediating Effect of the Participants' Positive Emotions} The stepwise multiple regression analysis carried out with the scores of the CWB-S tendency as the dependent variable. The results showed that the positive effects of the participants' positive emotions in the process of leader positive emotions affecting the participants' CWB-S were significant (Table 8), H2 is confirmed in the laboratory context.

\subsubsection{Analysis of the Moderating Effect of Organizational Leadership Fairness} Multivariate analysis of variance performed with the score of the CWB-S tendency as the dependent variable. The results showed that there was a significant interaction between the leadership positive emotion and the organizational leadership justice (Figure 6), F $(1,110)=3829, p<0.05$. The results of the simple

Table 5. Leadership positive emotional situation operational effectiveness test.

\begin{tabular}{ccccc}
\hline Group & $\mathrm{n}$ & $\mathrm{M}$ & $S D$ & $T$ \\
\hline Leadership positive emotion group & 60 & 5.97 & 0.974 & $11.669^{* *}$ \\
Leadership neutral emotion group & 54 & 3.96 & 0.846 & \\
\hline
\end{tabular}

Note: ${ }^{* *}, p<0.01$.

Table 6. Leadership positive emotional situation operational effectiveness test.

\begin{tabular}{ccccc}
\hline Group & $\mathrm{n}$ & $\mathrm{M}$ & $S D$ & $T$ \\
\hline Leadership unfair group & 59 & 6.119 & 1.018 & $19.704^{* *}$ \\
Fair group & 55 & 2.255 & 1.075 & \\
\hline
\end{tabular}

Note: ${ }^{* *}, p<0.01$.

Table 7. Difference analysis table of CWB-S tendency of employee under different leadership emotional situations.

\begin{tabular}{ccccc}
\hline Group & $\mathrm{n}$ & $\mathrm{M}$ & $S D$ & $T$ \\
\hline Leadership unfair group & 59 & 6.119 & 1.018 & $19.704^{* *}$ \\
Leadership Fair group & 55 & 2.255 & 1.075 & \\
\hline
\end{tabular}

Note: ${ }^{* *}, p<0.01$. 
Table 8. Analysis of the mediating effect of the participants' positive emotions in the laboratory context.

\begin{tabular}{cccccccccccc}
\hline \multirow{2}{*}{ Predictor } & \multicolumn{3}{c}{ Model 0 CWB-S } & \multicolumn{3}{c}{ Model 1 Employee positive emotions } & \multicolumn{3}{c}{ Model 2 CWB-S } \\
\cline { 2 - 10 } & $\beta$ & SE & $\mathrm{t}$ & $\beta$ & $\mathrm{SE}$ & $\mathrm{t}$ & $\beta$ & SE & $\mathrm{t}$ \\
\hline gender & -0.192 & 0.105 & -1.825 & 0.046 & 0.15 & 0.306 & -0.183 & 0.101 & -1.807 \\
age & -0.005 & 0.018 & -0.264 & 0.043 & 0.025 & 1.691 & 0.004 & 0.017 & 0.246 \\
Leadership positive emotion & -0.119 & 0.036 & $-3.283^{* *}$ & 0.353 & 0.052 & $6.840^{* *}$ & -0.045 & 0.042 & -1.092 \\
Employee positive emotions & & & & & & & & -0.209 & 0.064 & $-3.251^{* *}$ \\
$\mathrm{R}^{2}$ & 0.104 & 0.318 & 0.183 & 0.104 & 0.318 & 0.183 & 0.104 & 0.318 & 0.183 \\
$\mathrm{R}^{2}$ & 0.080 & 0.300 & 0.154 & 0.080 & 0.300 & 0.154 & 0.080 & 0.300 & 0.154 \\
$\mathrm{~F}$ & $4.271^{* *}$ & $46.784^{* *}$ & $6.124^{* *}$ & $4.271^{* *}$ & $46.784^{* *}$ & $6.124^{* *}$ & $4.271^{* *}$ & $46.784^{* *}$ & $6.124^{* *}$ \\
\hline
\end{tabular}

Note: ${ }^{* *}, p<0.01 ;^{*}, p<0.05$.

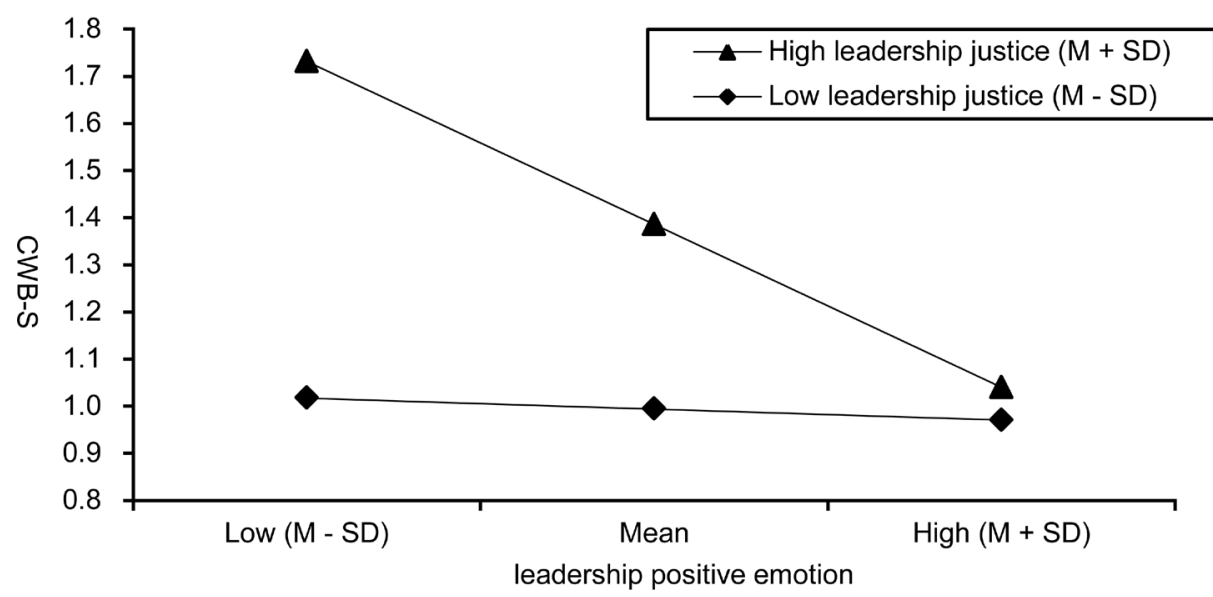

Figure 6. The moderating effect of leadership justice in the laboratory context.

effect test showed that the subjects who faced the leaders' unfairness will performed low CWB-S tendency when they felt leader's positive emotions ( $\mathrm{n}=$ 31) compared when they felt leader's neutral emotions $(n=28)$, and the difference get the level of significant $\mathrm{F}(1,108)=8.165, p<0.01$. The subjects who facing organizational justice situation could not perform difference between when they felt leadership positive emotions $(\mathrm{n}=29)$ and leadership neutral emotional $(\mathrm{n}=26)$. There is no significant difference in the score of CWB-S in this background, $\mathrm{F}(1,108)=0.001, p>0.05$, and hypothesis 3 is confirmed.

\subsection{Discussion}

The experiment found that by starting the positive emotional experience of the leader, there was a significant difference in the implementation of CWB among the individuals. Compared with the leadership neutral emotion group, the participants in the leadership positive emotion group showed a lower tendency of CWB-S. The results of this study, on the one hand, show that the event of the leader positive emotion can relief individual tendency of CWB-S, verifies the positive predictive effect of the leadership positive emotion on the negative be- 
havior of the employee, and consolidates Internal validity of the results of the research. On the other hand, this study provides improved direction and theoretical guidance for managers to prevent and reduce the employee CWB-S.

Specific to the results of this study, the reason why leaders' positive emotions have an impact on the tendency of employee CWB-S is because the leader's emotion perceived by the participants actively stimulated the participant through the emotional response path and the inferred path. Emotions made the participants appear in the sense of security and satisfaction, satisfied with the status of themselves, and then changed the decision-making tendency of CWB-S, prompting the subjects to make fewer CWB-S. The process also influenced by the participants' perception of organizational leadership's fairness in the experience. When the perceived organizational leadership justice was low, the effect that participants' tendency of CWB-S significantly affected by the positive emotions of the leader is increased. At this time, the positive emotion expressed by the leader in the process of influencing the CWB-S, the role of the emotional response path expanded. At this time, the subject has less reason for the reason of the emotion expressed by the leader, involuntarily reduce and CWB decisions.

\subsubsection{Analysis of the Mediating Effect of Employees' Positive Emotions}

Study 3 found that under the conditions of two different leadership emotions, the scores of their own positive emotions and their CWB-S tendency scores were significantly different, compared with the starting conditions of neutral leadership emotions, those participates who under the condition of positive emotion initiation were possess higher positive emotions, and their scores of the CWB-S were lower. This result was due to the Chinese "face" effect and the need for harmonious interpersonal relationships. When individuals face the positive emotions expressed by their immediate superiors, employees are also more inclined to respond emotions with same degree of positive, even if they have gaps because of past unfair leadership experiences, they still decide to keep peace in a short-term. Due to the peace status of employee, the individual's CWB towards the superior is less inclined.

\subsubsection{Differences Analysis in the CWB-S of the Employee in Different Organizations Justice and Leadership Emotion Situation}

The study found that individuals who feel organizational leadership unfair have significant differences in the scores of CWB-S tendencies between the conditions of two leadership emotion situations, and under the condition of leadership positive emotions, the individual's CWB-S tends to lower. But when individuals consider it is fair of leadership, those participates whatever under the conditions of leadership positive emotions or leadership neutral emotions have no significant difference in the scores of the CWB-S tendencies. The reason for this may be that the degree of leadership of the organization affects the employee's tolerance to other adverse factors, so that their behavior is not affected by leadership 
emotions, maintaining a high level of work enthusiasm and less The frequency of CWB-S. However, this process does not affect the mediating role of positive emotions when leadership positive emotions affecting individuals' tendency to CWB-S.

Specifically, individuals with low leadership justice are treated unfairly by their direct leader. Individuals believe that they neglected by credit, paying and not getting the reward they deserve, so they seek psychology balance by increasing CWB-S. In this situation, once its direct leadership does not show positive emotions, the frequency of the individual's CWB-S increases sharply. In this state, the individual does not care about other factors, and their CWB-S be seen as a kind of counterattack and revenge against unfair leadership, because the imbalance between individual input and output caused by their direct superiority. The individual can suppress his own CWB-S when the leader shows positive emotions, but the individual's CWB-S can be suppressed no more when the superior do not show positive emotions. In many studies, this phenomenon is also based on a certain explanation. The positive emotional feedback of the leader is a reward for the employees. Especially in the context of unfair leadership, the leadership positive emotion feedback is often seen as the compensation for the past unfair experience. When it is lost, the individual psychology once again enters the imbalance between input and output, the CWB-S appears.

\section{Conclusion}

Through questionnaire research and experimental research, this paper systematically discusses the internal psychological process of leadership emotions affecting employees' CWB, and explores the intermediary role played by employees' own emotions. This paper also explores the mediator-moderator role of employees' organizational justice, and draws the following conclusions:

1) Leadership emotion has a significant negative impact on employees' CWB

The results of this study show that leadership emotions have a significant negative impact on employees' CWB. Specifically, when the employees feel leader's emotion is positive, the employees will reduce or reduce the frequency of CWB. This conclusion is in line with the hypothetical expectations of the study.

2) Employees' emotions play a mediating role in the influence of leadership emotions on employee CWB

The results of this study show that employee emotions play a complete mediating role in the process of leadership positive emotions affecting employees' CWB. The influence of leadership positive emotions on employees' CWB is achieved by first affecting employees' own emotions and then affecting employees' CWB. Specifically, in the process of interpersonal interaction, the subordinate employees are more positive when they feel their leader expresses positive emotion, and the employees' positive emotion will further reduce their CWB tendencies and vice versa.

3) The direct effect of leadership emotions on employees' CWB moderated by 
employees' sense of leadership justice.

The analysis results of this study confirm that the mediating effect of employees' own emotions on the influence of leadership positive emotions on employees' CWB is moderated by employees' leadership justice. Specifically, when the employee has a low sense of leadership justice in the organization, the frequency of the employee's CWB pointing to the superior (CWB-S) is more susceptible to the influence of the leadership's positive emotions. At this time, the direct impact of the leaders' positive emotions affecting employee CWB-S increases in effectiveness: the less the positive emotion expressed by the leader, the higher the tendency of the employee CWB-S. Compared with the leadership unfair situations, the tendency of employee CWB-S in the situation of organizational justice is relatively unchangeable when they felt leader's emotion, and the direct effect of leadership positive emotions is not significant. The way that leadership's positive emotions change employees CWB-S is most by way of employee's own emotion.

Judging from the literature currently in this study, this is the first time to test the model of employee CWB that influenced by the employee's own emotions and influenced by the employee's organizational sense of fairness at the same time. This study also uses the way combining questionnaire research and experimental research. This study further reveals the "black box" of leadership positive emotions affecting employees' CWBs from the perspective of internal psychological processes and mechanisms. It expands the existing research perspective and expands the internal validity and external validity of the research conclusions. It also provides empirical evidence for understanding the influence mechanism of leadership positive emotions on employees' CWB. In addition, this study also explored the mediating effect of employee emotions between leadership emotions and employee CWBs, and the mediator-moderator role of organizational leadership justice. This research conclusion provides an in-depth understanding of internal mechanisms of leadership positive emotions and employee CWBs. This research has important value.

\section{Limitations and Implications}

\subsection{Limitations}

Through the detailed analysis of the literatures such as leadership emotions, employee CWBs, employee emotions and organizational justice, this study establishes leadership emotions, employee emotions, employee CWBs and organizational justice through the theory of emotions as social information theory. The theoretical research model empirically tests the relationship between leadership positive emotions and employees' CWBs and explores the mediating role of employee emotions and the mediating role of organizational justice. The conclusion of this study is of great significance to the theory that emotion, that is, social information theory, is both theoretical and practical. However, due to factors such as my ability, energy and time, this research still has many shortcomings. In view 
of these shortcomings, I hope to overcome it in future research.

First, the distribution of samples and the expansion of sample size. Although this study considers the geographical distribution of sample selection, samples taken from ten cities in South of China, North China, Central China, Northwest China, and East China. However, the sample size distribution in each region still has unevenness, which is limited to the researchers' social resources. There are more samples in the South China region, accounting for about $50 \%$ of the total sample. In the future research, the selection of the sample area should be more extensive, and the sample distribution should be average based on the further expansion of the sample size, so that the research results are more representative and persuasive.

Second, the problem of the extension of the mediation variable. This study starts from the theory of emotion as social information, provides a theoretical basis for the intermediary mechanism of research. And this study selects the emotional variables of employee's own emotion as the mediator to explore the influence process of leadership emotion on employees' CWB, but whether this process is still in the process. There are other mediating variables that should be explored in future research, thus enriching the research on the internal mechanism of leadership emotions affecting employees' CWB.

Third, the problem of exploring variables. Although this study draws the conclusion that organizational justice plays a regulatory role in the model of employee's own emotional leadership influence on employees' CWB, and discusses the different emotions expressed by leaders under the organizational fair background. How to influence the internal mechanism of employee CWB decision-making, but limited by my ability and energy, other adjustment variables such as personality traits, attribution style, etc. that may affect the direction and intensity of leadership emotions and employee CWB It is not involved. Therefore, future research can explore in this area.

\subsection{Theoretical Implications}

At present, the research on employee CWB with leadership positive emotion as an antecedent variable is less, and there is no research on the moderator effect of organizational justice at the process of leadership positive emotion affecting employee CWB. Therefore, the theory of this study, the meaning is mainly reflected in the following three aspects:

1) For the first time, the introduction of employee emotions as a mediator in the study of the relationship between leadership emotions and CWB, exploring the mediating role of employee emotions.

In the existing research, negative emotions, retaliation intentions, etc. are common mediators of CWB, and there is still no research on CWB with employees' positive emotions as mediator. But this study uses employee positive emotion as mediator to forecasting the process of leadership positive emotion affecting employee CWB, thus expanding the research space between leadership 
emotions and employee CWB.

2) The first empirical test examined the moderator role of organizational justice in the process of leadership positive emotions on employee CWB, and expanded related research.

This study not only tests the influence of leadership positive emotions on employees' CWB, but also further discovers the direct effect of leadership positive emotions affecting employee CWB become significant at the case of low leadership justice, Through the field research and laboratory experiments to reveal the inner mechanism of leadership positive emotions affecting employee CWB is the biggest innovation of this research.

\subsection{Practical Implications}

The research conclusions of this study can provide the following inspiration for organizational management practices:

First, the organization can organize emotional leadership training courses to reduce the emergence of employees' CWB by improving their emotional expression and emotional infection.

Second, how to improve employees' understanding of leadership emotions and strengthen their own emotional adjustment ability should become an important issue for the organization.

Third, the sense of organizational justice should not only emphasize the fairness of the system, the degree of fairness, but also emphasize the fairness of leadership, cultivate managers' awareness of leadership fairness, and plan managerial behavior.

Fourth, changes should be targeted in employees' CWBs, and multiple improvement strategies for organizational fairness and leadership sentiment expression for different types of employee CWB.

\section{Conflicts of Interest}

The authors declare no conflicts of interest regarding the publication of this paper.

\section{References}

Bensimon, H. F. (1994). Crisis and Disaster Management: Violations in the Workplace. Training and Development, 28, 27-32.

Greenberg, J. (1990). Employee Theft as a Reaction to Underpayment Inequity: The Hidden Cost of Paycuts. Journal of Applied Psychology, 75, 561-568. https://doi.org/10.1037/0021-9010.75.5.561

Harper, D. (1990). Spotlight Abuse-Save Profits. Industrial Distribution, 79, 47-51.

Huang, L., Yang, Y. Z., \& Ji, Z. M. (2003). Zheng xing fu xing qing xu liang biao de zhong guo ren qun shi yong xing yan jiu. [Applicability Study of Chinese Population with Positive Negative Emotion Scale.] Zhong Guo Xin Li Wei Sheng Za Zhi [Chinese Journal of Mental Health], 17, 54-56. https://doi.org/10.1088/0256-307x/27/3/032501

Jones, D. A. (2009). Getting Even with One’s Supervisor and One’s Organization: Rela- 
tionship among Types of Injustice, Desires for Revenge and Counterproductive Work Behavior. Journal of Organizational Behavior, 30, 525-542.

https://doi.org/10.1002/job.563

Liu, Y., \& Long, L. R. (2003). Zu zhi gong ping gan dui zu zhi xiao guo bian liang de ying xiang. [The Influence of Organizational Justice on Organizational Effect Variables.] Guan Li Shi Jie [Journal of Management World], 3.

Spector, P. E., Fox, S., Penney, L. M., Bruursema, K., Goh, A., \& Kessler, S. (2006). The Dimensionality of Counterproductivity: Are All Counterproductive Behaviors Created Equal? Journal of Vocational Behavior, 68, 446-460.

https://doi.org/10.1016/j.jvb.2005.10.005

Van Kleef, G. A. (2009). How Emotions Regulate Social Life: The Emotions as Social Information (EASI) Model. Current Directions in Psychological Science, 18, 184-188. https://doi.org/10.1111/j.1467-8721.2009.01633.x

Wen, Z. L., \& Ye, B. J. (2014). You tiao jie de zhong jie mo xing jian yan fang fa: jing zheng hai shi ti bu? [An Adjusted Mediation Model Test Method: Competition or Substitute?] Xin Li Xue Bao [Journal of Psychology], 46, 714-726.

$\mathrm{Xu}, \mathrm{M}$. (2015). Zu zhi bu gong ping yu fa sheng chan xing wei de guan xi yan jiu. [Research on the Relationship between Organizational Unfairness and Anti-Production Behavior.] Thesis, Nanjing: Nanjing Normal University.

Zhang, J. Y., \& Wang, W. Y. (2008). Wo guo gong zuo chang suo zhong fu mian xing wei ji fen xi. [Investigation and Analysis of Negative Behaviors in Chinese Workplaces.] Cai Mao Yan Jiu [Finance and Trade Research], 6, 101-107. 